\title{
A novel single base pair duplication in WDR62 causes primary microcephaly
}

\author{
Verena Rupp ${ }^{1}$, Sobiah Rauf ${ }^{2}$, Ishrat Naveed ${ }^{2}$, Windpassinger Christian ${ }^{1}$ and Asif Mir $^{2 *}$
}

\begin{abstract}
Background: Primary microcephaly is a disorder of the brain resulting in a reduced head circumference that can come along with intellectual disability but with hardly any other neurological abnormalities.

Case presentation: In this study we report on three Pakistani males from a consanguineous family with 2, 4 and 25 years, diagnosed with autosomal recessive primary microcephaly. By genotyping, Sanger sequencing and using bioinformatical approaches the disease causing mutation was identified and evaluated.

Conclusion: By using a 250K SNP array, we were able to detect an $11 \mathrm{Mb}$ large autozygous region in the MCPH2 locus on chromosome 19q13.12. Sequencing of the associated gene, WDR62, revealed the frameshift causing single base pair duplication, c.2527dupG. This mutation is predicted to affect the structural features of WDR62 which in turn changes the conformation and function of the protein. Aspartic acid (D) at position 843 was found to be conserved among various ortholog species. The present findings will be helpful in genetic diagnosis of patients and future studies of WDR62.
\end{abstract}

Keywords: Autosomal recessive primary microcephaly (MCPH), MCPH2 locus, WDR62, Mutation

\section{Background}

Autosomal recessive primary microcephaly $(\mathrm{MCPH})$ is a rare malformation of the head resulting in a circumference of at least 3 standard deviations below the mean for a given population, gender and age [1-3]. To date, 13 MCPH loci and their genes (MCPH1, WDR62, CDK5RAP2, CASC5, ASPM, CENPJ, STIL, CEP63, CEP135, CEP152, PHC1, CDK6 and HsSAS-6 respectively) have been mapped and identified, making this disease a genetically heterogeneous disorder, affecting 1 in 10000 children that result from consanguineous marriages [4-17]. Recent studies in Drosophila revealed the influence of mutations in $\mathrm{MCPH}$ genes on asymmetrical cell division having an adverse effect on neuronal growth in the central nervous system during embryogenesis [18-20]. Beside a reduced cerebral cortex, a mild-to-moderate intellectual disability that strongly correlates with the head circumference, and sometimes also a delay in the linguistic development, primary microcephaly patients in general have no other developmental or neurological deficits $[10,14,18,21]$.

\footnotetext{
* Correspondence: asif.mir@iiu.edu.pk

${ }^{2}$ Bioinformatics \& Biotechnology, International Islamic University, Islamabad, Pakistan

Full list of author information is available at the end of the article
}

Although sloping foreheads and reduced intelligence are very common, they are not listed as a basic criteria for the diagnosis of microcephaly $[19,22]$. The loci for $\mathrm{MCPH} 2$ on chromosome 19q13.12 has already been discovered in 1999 by Roberts et al. [23] but although excessive sequencing of this locus has been performed since then the corresponding gene, WDR62, remained undiscovered until only recently $[5,13,16]$. In human, two alternative transcripts are expressed. The full-length WDR62 gene consists of 32 exons resulting in a genomic size of 50230bp. It encodes for a 1523 amino acid long protein that comprises 15 WD-40 repeats, one CpG signal and a polyadenylation signal [13,19,24-26]. The homodimerization region can be found on the C-terminal domain which shows no sequence homologies to any known oligomerization signals [27]. First studies on WDR62 revealed it as a JNK scaffold protein that associates with the two JNK-signalling pathway proteins JNK (c-Jun N-terminal kinase) and MKK7 (MAP kinase kinase 7) and is recruited to stress granulaes upon cellular stress induction [28]. Although Bilgüvar et al [5] showed in expression experiments that WDR62 was rather a nuclear than a centrosomal protein, Bhat et al. [24] proved its centrosomal localization during mitosis as well as its nuclear localization but also suggested 
that the localization of WDR62 strongly depends on cell cycle phase and cell type. Only recently, WDR62 was identified as a phosphoprotein associated with mitotic spindle poles during prophase to metaphase transition but lacked its centrosomal localization during ana- and telophase. Depletion experiments led to a mitotic delay and to abnormal spindle formation as well as an increased formation of multipolar spindles [29].

A wide range of cortical malformations have been described for mutations in this gene, including microcephaly, pachygyria with cortical thickening, hypoplasia of the corpus callosum, polymicrogyria, simplified gyral patterns, cerebral hypoplasia, band heterotopias, lissencephlay and schizencephaly $[5,13,16,17,19,24,30]$. Due to the increased incidence of autozygous regions in children from consanguineous families, the probability of carrying a disease causing identical-by-decent mutation is increased in patients with autosomal recessive disorders [30]. Following this assumption, we were able to identify a novel homozygous mutation in WDR62 in a consanguineous Pakistani MCPH2 family.

\section{Case presentation}

\section{Sample collection}

After obtaining informed consent, blood was drawn and DNA was isolated from 9 family members, including two affected brothers and their affected relative, according to standard protocols.

\section{Genotyping}

Autozygosity mapping was performed with the Affymetrix GeneChip Human Mapping 250K Nsp Array according to

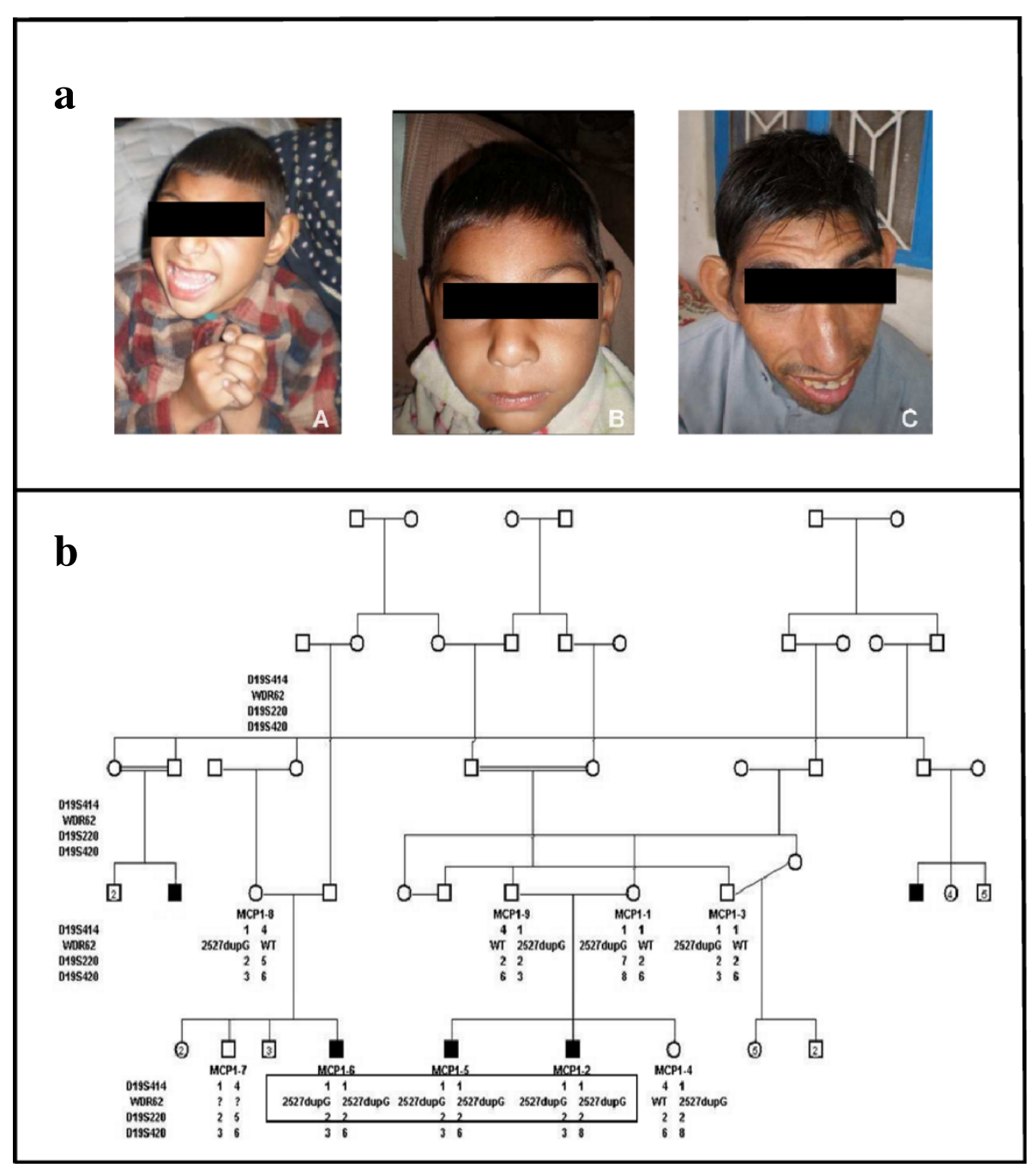

Figure 1 Family Pedigree and Genotypes: a) Members of families MCP1 displaying autosomal recessive primary microcephaly:Patient MCP1-2 (A), his brother MCP1-5 (B), patient MCP1-6 (C). b) Family pedigree and genotypes for 3 specific markers around chromosome $19 q 13.12$. Affected individuals share homozygous allele 1 for D19S414 and homozygous allele 2 for marker D19S220. Relative distances in Kosambi cM were achieved from the Marshfield linkage map (http://research.marshfieldclinic.org): cen-D19S414-7.48cMWDR62-0.54cM-D1S220-4.27cM-D1S420-tel. 
the manufacturer's protocol. The physical distance of the $\mathrm{LOH}$ region was determined via University of California Genome Browser UCSC [25]. Microsatellite markers in this region (D19S414, D19S220 and D19S420) were selected from ABI PRISM ${ }^{\circ}$ Linkage Mapping Set v2.5 for fine-mapping the disease locus and to analyze the segregation among the available family members. The resulting data were analyzed with Peak Scanner Software v1.0 (Applied Biosystems).

\section{Sanger sequencing}

WDR62 exons and their flanking intron junctions were determined with UCSC Browser. Primers were designed using ExonPrimer (http://ihg.helmholtzmuenchen.de/ihg/ ExonPrimer.html) and synthesized by Microsynth. Primer sequences are available on request.
WDR62 exons and their flanking intron sequences were amplified with HotStarTaq Master Mix Kit (Qiagen) using a standard amplification protocol, the sequencing reaction was set up with Big Dye Terminator 3.1 (Applied Biosystems) and remaining dye nucleotides were removed with Sephadex ${ }^{\text {Tix }}$ G-50 superfine (GE Healthcare). Analysis of the amplicons was performed on ABI 3130xl Genetic Analyzer.

\section{Computational analysis}

To predict the secondary structure of WDR62 protein, the online server Psipred [31] was used. MSA (Multiple Sequence Alignment) was performed using T-Coffee [32] to show the sequence consistency among various ortholog species of Human WDR62. Thirteen ortholog species with reference to Human (Homo sapiens) have

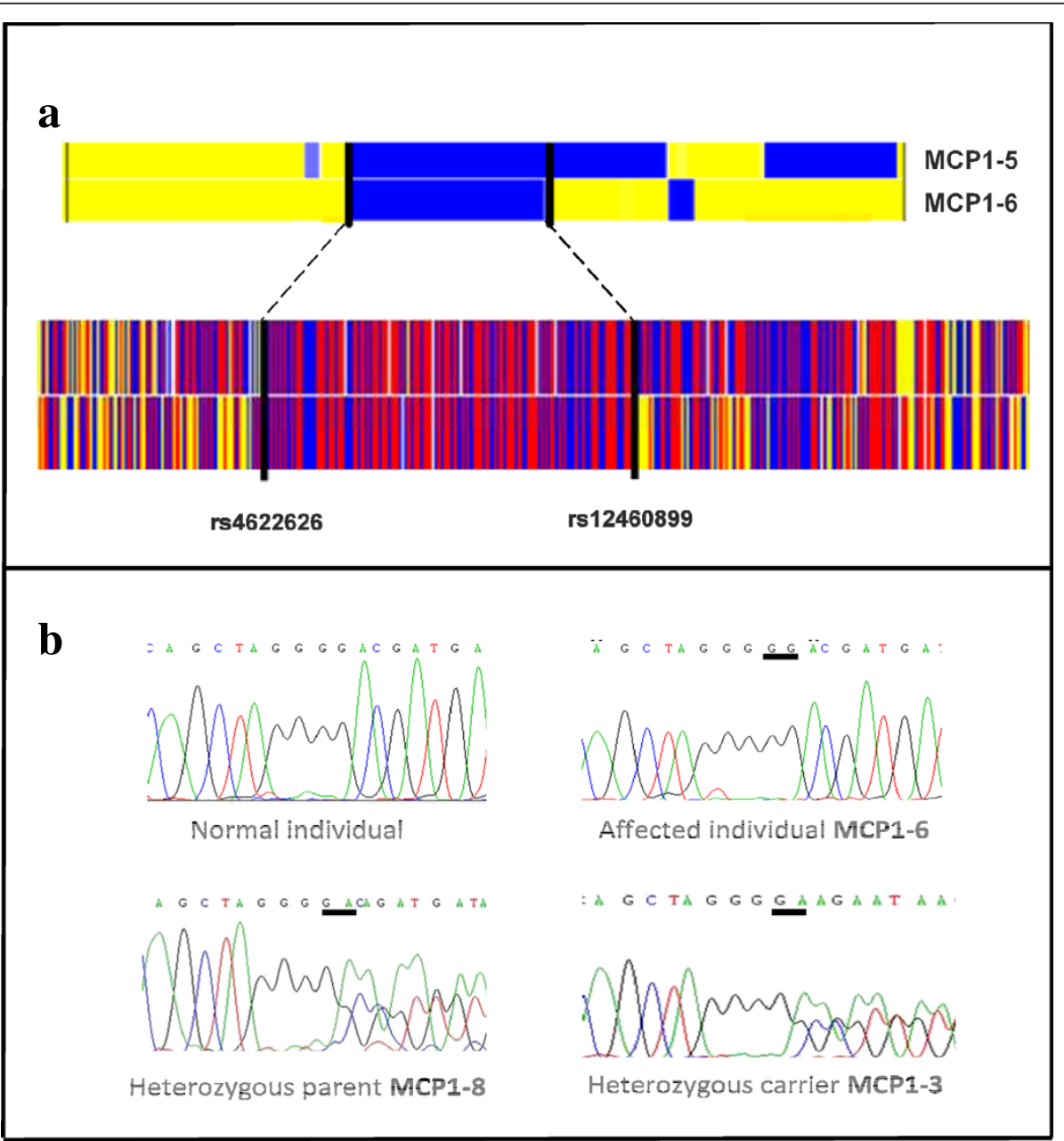

Figure 2 Results of Array and Sequencing: a) SNP NSP 250K array (Affimetrix) of Chromosome 19 of individuals (MCP1-5 and MCP1-6). Blue and red areas indicate homozygous regions, while yellow areas indicate heterozygous regions. Patients share the same homozygous haplotype on chr. 19q12-q13.2, indicating an autozygous region. Borders are defined as the first heterozygous SNP above and under the homozygous locus. b) Sanger sequencing traces confirm the homozygous mutation, c.2527dupG, in all affected individuals and heterozygous mutations in the parents (underlined in black). Despite having the same microsatellite marker alleles as the affected, individual MCP1-3 is heterozygous for c.2527dupG. 
been considered for this study. These species include: Chimpanzee (Pan troglodytes), Macaque (Macaca mulatta), Mouse (Mus musculus), Guinea Pig (Cavia porcellus), Megabat (Pteropus vampyrus), Dog (Canis familiaris), Opossum (Monodelphis domestica). Sequences of all ortholog species were collected through ensemble database.

\section{Findings}

Five individuals of a consanguineous Pakistani family from Kotli, in the Pakistani administered Kashmir, displayed phenotypical and behavioral characteristics for primary microcephaly. An autosomal recessive inheritance was assumed according to the pedigree. DNA was available from three patients, the brothers, MCP1-2 and MCP1-5, and their more distant relative, MCP1-6.

With 4 years and 6 months, male individual MCP1-2 (Figure 1a A) had a head circumference of only $37.47 \mathrm{~cm}$ and a height of $91.44 \mathrm{~cm}$. He was reported to show aggressive behavior, being unable to walk due to a disabled left leg and to have an abnormally watery mouth. Beside a head circumference of only $35.94 \mathrm{~cm}$ and a height of $74.93 \mathrm{~cm}$ his 2 year old brother, patient MCP1-5 (Figure 1a B), displays no other abnormalities.

The third 25 years old patient, MCP1-6 (Figure 1a C), has a head circumference of $39.37 \mathrm{~cm}$ and a height of 170 $\mathrm{cm}$. As for patient MCP1-2, aggressiveness and a watery mouth have been observed. The computed tomography (CT) scan of this individual revealed a reduced volume of the right cerebral hemisphere and prominent extra axial cerebrospinal (CSF) spaces with ill-defined gryal and nuclei pattern (Data not shown here). However, no local area of brain attenuation and intracerebral blood was observed. Due to the non-cooperative behavior of two other affected individuals (MCP1-2 and MCP1-5) detailed magnetic resonance imaging (MRI) scan could not be performed.

Autozygosity mapping of individuals MCP1-5 and MCP16 , revealed a single homozygous stretch on chromosome 19 , reaching from q13.11 to q13.12, bounded by the SNP markers rs12460899 (29,899 Mb) and rs4622626 (40,933 $\mathrm{Mb}$ ) (Figure 2a). Previously, the MCPH2 locus has been linked to $19 \mathrm{q} 13.12$, with the only recently indentified corresponding gene WDR62 [5,13,16,23]. Fine-mapping of this locus with 3 microsatellite markers, D19S414 (31, 9 $\mathrm{Mb})$, D19S220 (38,3 Mb) and D19S420 (43,7 Mb), identified a common homozygous stretch among the affected between markers D19S414 and D19S220 (Figure 1b). With WDR62 lying at 36,545-36,596 Mb, we screened individual MCP1-6 by Sanger sequencing for mutations within this gene and revealed a homozygous duplication (insertion) in exon 22, c.2527dupG. This duplication leads to a frameshift with a premature stop codon 4 amino acids after the start of the exon (p.Asp843Glyfs $* 3$ ).

Segregation of the duplication in the family was confirmed by sequencing (Figure 2b). Surprisingly healthy individual MCP1-3 displays the same marker alleles as the affected but is heterozygous for the mutation in exon 22. This can be explained by the obviously nonpolymorphic nature of the microsatellite markers we used for analyzing this family. Compared with the alleles of his brother, MCP1-9, a crossing over after the marker D19S414 has probably occurred. All known mutations for WDR62, including the one reported in this paper, are summarized in Table 1. According to Psipred results (Figure 3a) the mutated WDR62 structure was predicted

\section{Table 1 Cerebral cortical malformations causing} mutations detected in WDR62

\begin{tabular}{|c|c|c|c|c|}
\hline \multicolumn{2}{|l|}{ Mutation } & \multirow[b]{2}{*}{ Type $^{\text {a) }}$} & \multirow[b]{2}{*}{ Exon } & \multirow[b]{2}{*}{ First reported } \\
\hline DNA level & Protein level & & & \\
\hline c.193 G>A & p.Val65Met & $M$ & 2 & {$[13]$} \\
\hline c. $332 G>C$ & p.Arg111Thr & $M$ & 3 & {$[33]$} \\
\hline c.363delT & p.Asp122Metfsx5 & SD & 4 & [16] \\
\hline c.535_536insA & p.Met179fsx21 & $\mathrm{SI}$ & 5 & {$[24]$} \\
\hline c. $671 \mathrm{G}>C$ & p.Trp224Ser & $M$ & 6 & [13] \\
\hline c. $.900 C>A$ & p.Cys300Term & $\mathrm{N}$ & 8 & {$[24]$} \\
\hline c. $1043+1 G>A$ & p.Ser348ArgfsX63 & $\mathrm{S}$ & 8 & [16] \\
\hline c.1142delA & p.H381PfsX48 & SD & 9 & {$[33]$} \\
\hline c. $1194 G>A$ & p.Trp398Term & $N$ & 9 & [33] \\
\hline C. $1198 \mathrm{G}>\mathrm{A}$ & pGlu400Lys & $M$ & 9 & {$[34]$} \\
\hline c. $1313 G>A$ & p.Arg438His & $M$ & 10 & [13] \\
\hline c. $1408 C>T$ & p.Gln470Term & $N$ & 11 & {$[5]$} \\
\hline c.1531G > A & p.Aps511Asn & M & 11 & {$[13]$} \\
\hline c. $1576 G>A$ & p.Glu526Lys & $M$ & 12 & {$[5]$} \\
\hline c.1576G > T & p.Glu526Term & $\mathrm{N}$ & 12 & {$[5]$} \\
\hline c. $1942 C>T$ & p.GIn648Term & $\mathrm{N}$ & 15 & {$[35]$} \\
\hline c.2083delA & p.Ser696AlafsX4 & $\mathrm{SD}$ & 17 & {$[36]$} \\
\hline c. $2115 C>G$ & p.Gly705Gly & $\mathrm{CS}$ & 17 & {$[37]$} \\
\hline c.2527dupG & p.Asp843GlyfsX3 & $\mathrm{SI}$ & 22 & Present study \\
\hline c.2472_2473delAG & p.GIn918GlyfsX18 & SD & 23 & {$[36]$} \\
\hline $\begin{array}{l}\text { c. } 2867+4 \_c 2867+ \\
\text { 7delGGTG }\end{array}$ & p.Ser956CysfsX38 & SD & 23 & [16] \\
\hline c.2864-2867delACAG & p.D955AfsX112 & $\mathrm{SD}$ & 23 & {$[38]$} \\
\hline c. $3232 \mathrm{G}>\mathrm{A}$ & p.Ala1078Thr & M & 27 & {$[13]$} \\
\hline c.3361delG & p.Ala1121GlnfsX5 & SD & 28 & {$[33]$} \\
\hline c. $3503 G>A$ & p.W1168Term & $\mathrm{N}$ & 29 & [33] \\
\hline $\begin{array}{l}\text { c.3839_3855delGCC } \\
\text { AAGAGCCTGCCCTG }\end{array}$ & p.Gly1280AlafsX21 & SD & 30 & {$[5]$} \\
\hline c.3936dupc & p.Val1314ArgfsX18 & $\mathrm{SI}$ & 30 & {$[13]$} \\
\hline c.4205delTGCC & p.V1402GfsX12 & SD & 31 & {$[5]$} \\
\hline c.4241dupT & p.Leu1414LeufsX41 & $\mathrm{SI}$ & 31 & {$[13]$} \\
\hline c.1821dupT & p.Arg608SerfsX26 & l & 14 & [39] \\
\hline
\end{tabular}

a) $\mathrm{M}=$ Missense, $\mathrm{N}=$ Nonsense, $\mathrm{S}=$ Splice-site affecting mutation, $\mathrm{SI}=$ small insertion, $\mathrm{SD}=$ Small deletion, $\mathrm{CS}=$ Cryptic splice site. 


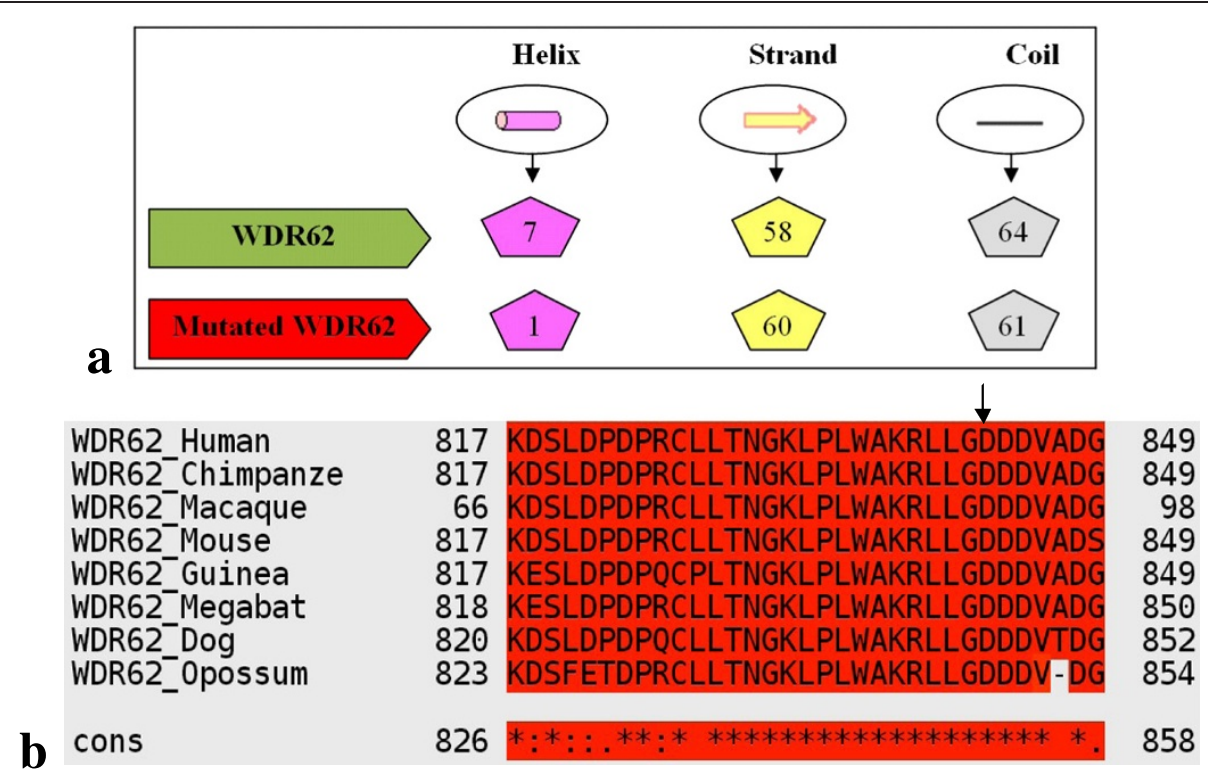

Figure 3 Bioinformatics Analysis: a) Comparison of predicted numbers of structural features using Psipred for normal and mutated WDR62; b) T-Coffee Results: Multiple Sequence Alignment for Human WDR62 gene. Conservation of amino acid D at position 843 among various ortholog species is indicated by arrow.

to consist of 61 coils, 60 strands and 1 helix compared to 64 coils, 58 strands and 7 helixes in the wild type. This not only affects the conformation but also the function of the protein. T-Coffee result (Figure $3 \mathrm{~b}$ ) shows that Aspartic acid (D, replaced by Glycine as a result of the mutation) at position 843 (indicated by an arrow head) is highly conserved among various orthologous species which indicates the importance of this amino acid.

\section{Conclusion}

According to Mahmood et al. [19] ASPM (MCPH5 locus) and WDR62 (MCPH2) are the two most common genes for primary microcephaly found mutated in more than $55 \%$ of the affected families. $4 \%$ of all MCPH cases are only due to mutations in WDR62 [35].

Due to the high prevalence of $\mathrm{MCPH} 2$ in primary microcephaly cases among consanguineous families more mutations in this gene will probably be revealed in the upcoming years. However, the high frequency of WDR62 mutations in consanguineous primary microcephaly patients will especially simplify the clinical counseling and diagnostic screening of non-consanguineous primary microcephaly patients.

\section{Consent}

We have obtained the written informed consent from the patient for publication of this case report and any accompanying images. A copy of the written consent is available for review from the Editor of this journal.

\section{Competing interests}

The authors declare that they have no competing interests.

\section{Authors' contributions}

The work presented here was carried out in collaboration between all authors. VR, WC, AM defined the research theme, designed methods, analyzed the data, interpreted the results and helped in writing the paper. SR identified the family and facilitate the diagnosis process and carried out Bioinformatics analysis. IN helped us with revisions of paper. All authors have contributed to, seen, read and approved the manuscript.

\section{Acknowledgements}

We are thankful to the family members for participation in our study.

\section{Author details}

'Institute of Human Genetics, Medical University of Graz, Graz, Austria.

${ }^{2}$ Bioinformatics \& Biotechnology, International Islamic University, Islamabad, Pakistan.

Received: 29 April 2014 Accepted: 10 September 2014 Published online: 11 October 2014

\section{References}

1. Passemard S, Kaindl AM, Titomanlio L, Gerard B, Gressens P: Primary autosomal recessive microcephaly. In GeneReviews. Edited by Pagon RA, Bird TD, Dolan CR, Stephens K. Seattle, Seattle (WA): University of Washington; 1993.

2. Roberts E, Hampshire DJ, Pattison L, Springell $K$, Jafri H: Autosomal recessive primary microcephaly: an analysis of locus heterogeneity and phenotypic variation. J Med Genet 2002, 39:718-721.

3. Thornton GK, Woods CG: Primary microcephaly: do all roads lead to rome? Trends Genet 2009, 25:501-510.

4. Awad S, Al-Dosari MS, Al-Yacoub N, Colak D, Salih MA: Mutation in PHC1 implicates chromatin remodeling in primary microcephaly pathogenesis. Hum Mol Genet 2013, 22:22002213.

5. Bilguvar K, Ozturk AK, Louvi A, Kwan KY, Choi M, Tatli B, Yalnızoğlu D, Tüysüz B, Çağlayan AO, Gökben S, Kaymakçalan H, Barak T, Bakırcıoğlu M, Yasuno K, Ho W, Sanders S, Zhu Y, Yllmaz S, Dinçer A, Johnson MH, Bronen 
RA, Koçer N, Per H, Mane S, Pamir MN, Yalçınkaya C, Kumandaş S, Topçu M, Özmen M, Sestan N, et al: Whole-exome sequencing identifies recessive WDR62 mutations in severe brain malformations. Nature 2010, 467:207-210.

6. Bond J, Roberts E, Mochida GH, Hampshire DJ, Scott S, Askham JM, Springel K, Mahadevan M, Crow YJ, Markham AF, Walsh CA, Woods CG: ASPM is a major determinant of cerebral cortical size. Nat Genet 2002, 32:316-320.

7. Bond J, Roberts E, Springell K, Lizarraga SB, Scott S, Higgins J, Hampshire DJ, Morrison EE, Leal GF, Silva EO, Costa SMR, Baralle D, Raponi M, Karbani G, Rashid Y, Jafri H, Bennett C, Corry P, Walsh CA, Woods CG: A centrosomal mechanism involving CDK5RAP2 and CENPJ controls brain size. Nat Genet 2005, 37:353-355.

8. Genin A, Desir J, Lambert N, Biervliet M, Van Der AAN: Kinetochore KMN network gene CASC5 mutated in primary microcephaly. Hum Mol Genet 2012, 21:5306-5317.

9. Guernsey DL, Jiang H, Hussin J, Arnold M, Bouyakdan K, Scott Perry S, Tina Babineau-Sturk T, Jill Beis J, Nadine Dumas N, Susan C, Evans SC, Ferguson M, Matsuoka M, Macgillivray C, Nightingale M, Patry L, Rideout AL, Thomas A, Orr A, Hoffmann I, Michaud JL, Awadalla P, Meek DC, Ludman M, Samuels ME: Mutations in centrosomal protein CEP152 in primary microcephaly families linked to MCPH4. Am J Hum Genet 2010, 87:40-51.

10. Hussain MS, Baig SM, Neumann S, Nurnberg G, Faroog M, Ahmad I, Alef T, Hennies HC, Technau M, Altmüller J, Frommolt P, Thiele H, Noegel AA, Nürnberg P: A truncating mutation of CEP135 causes primary microcephaly and disturbed centrosomal function. Am J Hum Genet 2012, 90:871-878.

11. Hussain MS, Baig SM, Neumann S, Peche VS, Szczepanski S: CDK6 associates with the centrosome during mitosis and is mutated in a large pakistani family with primary microcephaly. Hum Mol Genet 2013,

12. Kumar A, Girimaji SC, Duvvari MR, Blanton SH: Mutations in STIL, encoding a pericentriolar and centrosomal protein, cause primary microcephaly. Am J Hum Genet 2009, 84:286-290.

13. Nicholas AK, Khurshid M, Desir J, Carvalho OP, Cox JJ, Thornton G, Kausar R, Ansar M, Ahmad W, Verloes A, Passemard S, Misson JP, Lindsay S, Gergely F, Dobyns WB, Roberts E, Abramowicz M, Woods CG: WDR62 is associated with the spindle pole and is mutated in human microcephaly. Nat Genet 2010, 42:1010-1014.

14. O'Driscoll M, Jackson AP, Jeggo PA: Microcephalin: a causal link between impaired damage response signalling and microcephaly. Cell Cycle 2006, 5:2339-2344.

15. Sir JH, Barr AR, Nicholas AK, Carvalho OP, Khurshid M, Sossick A, Reichelt S, D'Santos C, Woods CG, Gergely F: A primary microcephaly protein complex forms a ring around parental centrioles. Nat Genet 2011, 43:1147-1153.

16. Yu TW, Mochida GH, Tischfield DJ, Sgaier SK, Flores-Sarnat L, Sergi CM, Topçu M, McDonald MT, Barry BJ, Felie JM, Sunu C, Dobyns WB, Folkerth RD, Barkovich AJ, Walsh CA: Mutations in WDR62, encoding a centrosome-associated protein, cause microcephaly with simplified gyri and abnormal cortical architecture. Nat Genet 2010, 42:1015-1020.

17. Khan MA, Rupp VM, Orpinell M, Hussain MS, Altmuller J, Steinmetz MO, Enzinger C, Thiele H, Hohne W, Nurnberg G, Baig SM, Ansar M, Nurnberg P, Vincent JB, Speicher MR, Gonczy P, Windpassinger C: A missense mutation in the PISA domain of HsSAS-6 causes autosomal recessive primary microcephaly in a large consanguineous Pakistani family. Hum Mol Genet 2014, doi:10.1093/hmg/ddu318

18. Cox J, Jackson AP, Bond J, Woods CG: What primary microcephaly can tell us about brain growth. Trends Mol Med 2006, 12:358-366.

19. Mahmood S, Ahmad W, Hassan MJ: Autosomal recessive primary microcephaly (MCPH): clinical manifestations, genetic heterogeneity and mutation continuum. Orphanet J Rare Dis 2011, 6:39.

20. Wollnik B: A common mechanism for microcephaly. Nat Genet 2010, 42:923-924

21. Jackson AP, Eastwood H, Bell SM, Adu J, Toomes C, Carr IM, Roberts E, Hampshire DJ, Crow YJ, Mighell AJ, Karbani G, Jafri H, Rashid Y, Mueller RF, Markham AF, Woods CG: Identification of microcephalin, a protein implicated in determining the size of the human brain. Am J Hum Genet 2002, 71:136142.

22. Teebi AS, Al-Awadi SA, White AG: Autosomal recessive nonsyndromal microcephaly with normal intelligence. Am J Med Genet 1987, 26:355-359.

23. Roberts E, Jackson AP, Carradice AC, Deeble VJ, Mannan J: The second locus for autosomal recessive primary microcephaly $(\mathrm{MCPH} 2)$ maps to chromosome 19q13.1-13.2. Eur J Hum Genet 1999, 7:815-820.
24. Bhat V, Girimaji S, Mohan G, Arvinda $H$, Singhmar P, Duvvari MR, Kumar A: Mutations in WDR62, encoding a centrosomal and nuclear protein, in indian primary microcephaly families with cortical malformations. Clin Genet 2011, 80:532-540.

25. Kent WJ, Sugnet CW, Furey TS, Roskin KM, Pringle TH: The human genome browser at UCSC. Genome Res 2002, 12:996-1006.

26. Consortium UP: Reorganizing the protein space at the universal protein resource (UniProt). Nucleic Acids Res 2012, 40:D71-D75.

27. Cohen-Katsenelson K, Wasserman T, Darlyuk-Saadon I, Rabner A: Identification and analysis of a novel dimerization domain shared by various members of JNK scaffold proteins. J Biol Chem 2013, 288:7294-7304.

28. Wasserman T, Katsenelson $K$, Daniliuc $S$, Hasin T, Choder M, Aronheim A: A novel c-jun $\mathrm{N}$-terminal kinase (JNK)-binding protein WDR62 is recruited to stress granules and mediates a nonclassical JNK activation. Mol Biol Cell 2010, 21:117-130.

29. Bogoyevitch MA, Yeap YY, Qu Z, Ngoei KR, Yip YY: WD40-repeat protein 62 is a JNKphosphorylated spindle pole protein required for spindle maintenance and timely mitotic progression. J Cell Sci 2012, 125:5096-5109,

30. Petukhova L, Shimomura Y, Wajid M, Gorroochurn P, Hodge SE: The effect of inbreeding on the distribution of compound heterozygotes: a lesson from lipase $\mathrm{H}$ mutations in autosomal recessive woolly hair/ hypotrichosis. Hum Hered 2009, 68:117-130.

31. McGuffin LJ, Bryson K, Jones DT: The PSIPRED protein structure prediction server. Bioinformatics 2000, 16:404-405.

32. Notredame C, Higgins DG, Heringa J: T-coffee: a novel method for fast and accurate multiple sequence alignment. J Mol Biol 2000, 302:205-217.

33. Memon MM, Raza Sl, Basit S, Kousar R, Ahmad W, Ansar M: A novel WDR62 mutation causes primary microcephaly in a pakistani family. Mol Biol Rep 2013, 40:591-595.

34. Bacino CA, Arriola LA, Wiszniewska J, Bonnen PE: WDR62 missense mutation in a consanguineous family with primary microcephaly. Am J Med Genet A 2012, 158A:622-625.

35. Kousar R, Hassan MJ, Khan B, Basit S, Mahmood S: Mutations in WDR62 gene in pakistani families with autosomal recessive primary microcephaly. BMC Neurol 2011, 11:119.

36. Murdock DR, Clark GD, Bainbridge MN, Newsham I, Wu YQ, Muzny DM, Cheung SW, Gibbs RA, Ramocki MB: Whole-exome sequencing identifies compound heterozygous mutations in WDR62 in siblings with recurrent polymicrogyria. Am J Med Genet A 2011, 155:2071-2077.

37. Najmabadi H, Hu H, Garshasbi M, Zemojtel T, Abedini SS, Chen W, Hosseini M, Behjati F, Haas S, Jamali P, Zecha A, Mohseni M, Püttmann L, Vahid LN, Jensen C, Moheb LA, Bienek M, Larti F, Mueller I, Weissmann R, Darvish H, Wrogemann K, Hadavi V, Lipkowitz B, Esmaeeli-Nieh S, Wieczorek D, Kariminejad R, Firouzabadi SG, Cohen M, Fattahi Z: Deep sequencing reveals 50 novel genes for recessive cognitive disorders. Nature 2011, 478:57-63.

38. Farag HG, Froehler S, Oexle K, Ravindran E, Schindler D, Staab T, Huebner A, Kraemer N, Chen W, Kaindl AM: Abnormal centrosome and spindle morphology in a patient with autosomal recessive primary microcephaly type 2 due to compound heterozygous WDR62 gene mutation. Orphanet J Rare Dis 2013, 8:1172-1178.

39. McDonell LM, Warman Chardon J, Schwartzentruber J, Foster D, Beaulieu CL, FORGE Canada Consortium, Majewski J, Bulman DE, Boycott KM: The utility of exome sequencing for genetic diagnosis in a familial microcephaly epilepsy syndrome. BMC Neurol 2014, 14:22.

doi:10.1186/s12881-014-0107-4

Cite this article as: Rupp et al:: A novel single base pair duplication in WDR62 causes primary microcephaly. BMC Medical Genetics 2014 15:107. 